\title{
Intracranial tumours during the first two years of life: presenting features
}

\author{
G S Gordon, S J Wallace, J W Neal
}

\begin{abstract}
Between 1979 and 1994, 21 children (nine females, 12 males) with intracranial tumours diagnosed before the age of 2 years (range 2-23 months) were treated at the University Hospital of Wales. The commonest presenting symptoms were vomiting $(n=9)$ and unsteadiness $(n=8)$; the commonest presenting sign was enlarged occipitofrontal circumference (>97th centile in 16 and $>90$ th centile in a further two). In five cases with signs of raised intracranial pressure, meningitis was the clinical diagnosis, and a lumbar puncture was performed. For cases with long delays in diagnosis, multiple other disorders had been considered and the significance of head enlargement had not been recognised. In very early childhood, intracranial tumours are uncommon and can mimic other disorders, especially meningitis. Early neuroimaging is advised when a child presents with recent onset of neurological symptoms and a disproportionately large head.
\end{abstract}

(Arch Dis Child 1995; 73: 345-347)

University Hospital of Wales, Heath Park, Cardiff CF4 4XW, Department of Child Health

G S Gordon

S J Wallace

\section{Department of} Neuropathology J W Neal

Correspondence to: Dr Wallace.

Accepted 17 May 1995
Keywords: intracranial tumour, infancy, presenting features.

Intracranial tumours presenting in the first 2 years of life are uncommon in general paediatric practice. Nevertheless they account for approximately $13 \%$ of childhood brain tumours. ${ }^{1}$ They are distinct in presentation and pathology. With a five year survival rate of $36 \%$ - compared to $57 \%$ in children

Table 1 Ages at onset of symptoms and at diagnosis: sites and pathology of tumours

\begin{tabular}{|c|c|c|c|c|}
\hline $\begin{array}{l}\text { Patient } \\
\text { No }\end{array}$ & $\begin{array}{l}\text { Age at } \\
\text { diagnosis } \\
\text { (months) }\end{array}$ & $\begin{array}{l}\text { Time } \\
\text { from symptom } \\
\text { onset to diagnosis }\end{array}$ & Origin & Pathology \\
\hline 1 & 11 & 7 Months & $\mathbf{S}$ & Oligodendroglioma \\
\hline 2 & 20 & 5 Months & I & Ependymoma \\
\hline 3 & 24 & 3 Months & I & Ependymoma \\
\hline 4 & 17 & 3 Months & I & Astrocytoma \\
\hline 5 & 13 & 4 Months & s & Astrocytoma \\
\hline 6 & 17 & 4 Months & S & Craniopharyngioma \\
\hline 7 & 24 & 3 Months & I & Primitive neuroectodermal tumour \\
\hline 8 & 2 & 1.5 Months & I & Medulloblastoma \\
\hline 9 & 12 & 2 Weeks & I & Medulloblastoma \\
\hline 10 & 8 & 2 Weeks & $\mathrm{s}$ & Angioma \\
\hline 11 & $12 \cdot 5$ & 2 Weeks & s & Choroid plexus carcinoma \\
\hline 12 & $20 \cdot 5$ & 2 Weeks & I & Ependymoma \\
\hline 13 & 6 & 2 Days & S & Choroid plexus papilloma \\
\hline 14 & 18 & 2 Days & S & Astrocytoma \\
\hline 15 & 5 & 1 Day & $\mathrm{s}$ & Fibrosarcoma \\
\hline 16 & 14 & 4 Months & $\mathbf{S}$ & Choroid plexus papilloma \\
\hline 17 & 23 & 7.5 Months & $S$ & Astrocytoma \\
\hline 18 & 22 & 2 Months & I & Medulloblastoma \\
\hline 19 & 19 & 1.5 Months & I & Astrocytoma \\
\hline 20 & 15 & 1 Month & I & Ependymoma \\
\hline 21 & 22 & 1 Month & I & Medulloblastoma \\
\hline
\end{tabular}

$\mathrm{S}=$ supratentorial; $\mathrm{I}=$ infratentorial .

aged 10 to 14 years - their prognosis is worse. ${ }^{12}$

Many of the presenting symptoms are common to other more prevalent childhood disorders. In babies in particular, tumour signs and symptoms may be attributed to developmental defects. ${ }^{1}$ A low index of suspicion may delay diagnosis. This could worsen the prognosis.

In order to highlight features that might facilitate early recognition, and thus contribute to an improved prognosis with current treatment, the presenting features of young children who were seen at the University Hospital of Wales (UHW), Cardiff, over a 15 year period are reviewed.

\section{Methods}

Between 1979 and 1994, 21 children aged less than 2 years with intracranial tumours were treated at UHW. Their notes were reviewed. The presenting features, tumour type and site of origin, and the ages at onset of symptoms, first presentation to a paediatric unit, and diagnosis were recorded. Children with neurocutaneous syndromes were excluded.

Computed tomography (CT) or magnetic resonance imaging (MRI) had been performed in all cases. Biopsy specimens were available in all cases. Approval for the study was obtained from the local ethics committee.

\section{Results}

Twelve patients were male, and nine female. Six were aged less than 1 year at diagnosis. Tumour type, site, and patients' ages are shown in table 1. Anatomical locations are listed in table 2 . Nine of 21 tumours were supratentorial and three of these occurred in infancy. Nine of 12 infratentorial tumours occurred in children over 12 months. The commonest tumour types were: astrocytoma, 5; ependymoma, 4; and medulloblastoma, 4.

The interval between onset of symptoms and diagnosis ranged from seven months to less than one day. Nine children had symptoms for at least three months before diagnosis. Even after presentation to a general paediatric unit, the diagnosis was made immediately - on clinical grounds - in only five children, and in less than one month in 14. Delays of between two and seven months, after contact with a paediatrician occurred in five cases.

Symptoms and signs are recorded in tables 3 and 4 . The commonest symptom was vomiting, found in nine children, of whom only three had early morning vomiting. The next most common symptoms were unsteadiness in eight 
Table 2 Anatomical locations of tumours

\begin{tabular}{lc}
\hline Supratentorial & 9 \\
Hemisphere & $(4)$ \\
Midline & $(2)$ \\
Suprasellar & $(3)$ \\
Infratentorial & 12 \\
Midline & $(7)$ \\
IVth ventricle & $(3)$ \\
Cerebellar hemisphere & $(2)$ \\
\hline
\end{tabular}

children, and head pain, described by two children, but assumed to be present in another five who were irritable or holding their heads. All children with recognised unsteadiness were aged over 12 months and seven of these had infratentorial tumours. Of four children in whom enlarged heads were noted before hospital admission, two were recognised incidentally at routine clinic visits.

When examined at presentation to a paediatric unit, 18 of 21 children had heads which were larger than expected: of these, the head circumference exceeded the 97 th centile for age in 16, and was between the 90th and 97 th centiles in two. For one child, no record of the head measurement at presentation was available. Eight of the 12 children with infratentorial tumours were ataxic. Otherwise, a wide range of non-localising signs was found. Abnormalities of the optic discs were observed in less than half the children. Three of these had open fontanelles.

An initial diagnosis of meningitis was made in five of 21 patients (patients 11-15). All underwent lumbar puncture before neuroimaging. Cerebrospinal fluid (CSF) pleocytosis was not associated with organisms either on Gram stain or culture. One child (patient 12) received 2 weeks of antituberculous treatment before his deteriorating clinical state prompted an urgent CT scan and immediate neurosurgical intervention.

Patient 1 exemplifies difficulties with establishing the diagnosis. He first presented at 11 weeks of age with apnoeic spells, when ultrasound scan of the head, electroencephalograph, and skull $x$ ray were normal. Five weeks later, a further apnoeic episode and the finding of a full fontanelle occasioned hospital admission: a CT scan showed cerebral oedema and the CSF was normal. Epileptic seizures, which started at the age of 4 months, became more focal by 7 months. Further neuroimaging revealed the tumour.

Table 3 Symptoms and tumour location

\begin{tabular}{llll}
\hline & \multicolumn{2}{l}{ Location of tumour } & \\
\cline { 2 - 3 } & $\begin{array}{l}\text { Supratentorial } \\
(n=9)\end{array}$ & $\begin{array}{l}\text { Infratentorial } \\
(n=12)\end{array}$ & $\begin{array}{l}\text { Total } \\
(n=21)\end{array}$ \\
\hline Symptoms & 4 & 5 & 9 \\
Vomiting & 1 & 7 & 8 \\
Unsteadiness & 2 & 5 & 7 \\
Pyreadache and related symptom & 4 & 1 & 5 \\
Decreased consciousness & 3 & 3 & 5 \\
Enlarged head & 1 & 3 & 3 \\
Opisthotonic episodes & - & 3 & 3 \\
Head tilt & 2 & - & 2 \\
Failure to thrive & 1 & - & 1 \\
Lethargy & 1 & - & 1 \\
Seizures & 1 & & 4 \\
Polydipsia/polyuria & & & \\
\hline
\end{tabular}

\section{Discussion}

The commonest tumours found throughout childhood are medulloblastomata and low grade supratentorial astrocytomata. However, very young children have a higher incidence of high grade astrocytomas, ependymomas, and primitive neuroectodermal tumours. ${ }^{1}$ Of the supratentorial tumours, astrocytoma was the most frequent in our series. Choroid plexus tumours, found in three of our patients (two with papillomas and one with a carcinoma) are particularly common in this age group, where the incidence is up to 10 times higher than in older children. Of the infratentorial tumours, we found - as have others ${ }^{2-4}$ - that ependymomas and medulloblastomas occurred most often.

The locations of medulloblastomas and ependymomas, the latter commonly arising from the ependymal cells lining the floor of the fourth ventricle, explain the almost universal presence (seen in seven of our eight cases) of hydrocephalus. Choroid plexus carcinomas, though rare in infancy, usually arise in the lateral ventricle; and, although central nervous system tumours may seed throughout the cerebrospinal fluid pathway, ${ }^{5}$ it is unusual to find this particular type of tumour in the posterior fossa.

In the first 6 months of life, tumours are predominantly supratentorial. Later, there is increasing involvement of structures below the tentorium until by the second year there is an infratentorial predominance. ${ }^{1-36}$ Although in our series three quarters of infratentorial lesions were in children over 12 months, only three supratentorial tumours occurred before this age. Fifteen of 21 tumours appeared to originate in midline structures. In early life, the predilection for the central neural axis, often resulting in obstruction to the flow of CSF, has been noted previously. ${ }^{2}$

Symptoms and signs of intracranial tumours result either from raised intracranial pressure or from local effects related to tumour position or spread, or from a combination of these. ${ }^{1-36}$ Twelve of our cases presented with symptoms of raised intracranial pressure, four with local effects, and five with both. Vomiting, which is one of the commonest signs of raised intracranial pressure but is not necessarily restricted to the early morning, occurred in nine of our patients. This symptom is easily attributable to more common illnesses encountered in daily paediatric practice, but occasionally may also be secondary to tumour invasion of the floor of the fourth ventricle. ${ }^{1}$ Very young children rarely complain of headache, even if they are able to speak, but may show a change in behaviour, become irritable, or hold their heads; symptoms which are prominent features of intracranial tumours at this age. 67

Papilloedema is often absent in children who have raised intracranial pressure, particularly if the fontanelle is open or the tumour is growing fast. ${ }^{4}$ Only 10 of our series had optic disc abnormalities, although 18 had enlarged heads at presentation. In babies, unfused cranial sutures allow the skull to expand readily 
Table 4 Signs and tumour location

\begin{tabular}{|c|c|c|c|}
\hline \multirow[b]{2}{*}{ Signs } & \multicolumn{2}{|c|}{ Location of tumour } & \multirow[b]{2}{*}{$\begin{array}{l}\text { Total } \\
(n=21)\end{array}$} \\
\hline & $\begin{array}{l}\text { Supratentorial } \\
(n=9)\end{array}$ & $\begin{array}{l}\text { Infratentorial } \\
(n=12)\end{array}$ & \\
\hline Enlarged OFC & 8 & 10 & 18 \\
\hline Ataxia & 1 & 8 & 9 \\
\hline Hyperreflexia & 1 & 8 & 9 \\
\hline Swollen optic discs & 5 & 5 & 10 \\
\hline Sunset sign & - & 2 & 2 \\
\hline Tense anterior fontanelle & 3 & 3 & 6 \\
\hline Pyrexia & 4 & 1 & 5 \\
\hline Extensor posturing & 3 & 2 & 5 \\
\hline Decreased consciousness & 3 & 2 & 5 \\
\hline Crackpot sign & - & 3 & 3 \\
\hline Weight $<3$ rd centile & 2 & - & 2 \\
\hline Facial weakness & 1 & 1 & 2 \\
\hline Sluggish, dilated pupils & 1 & i & 2 \\
\hline Neck stiffness & - & 1 & $\overline{1}$ \\
\hline Ptosis & - & 1 & 1 \\
\hline
\end{tabular}

$\mathrm{OFC}=$ occipitofrontal circumference.

in the presence of raised pressure. Such accommodation can mean further delay in the development of symptoms and signs. Two symptomless infants with enlarged heads and no other signs were identified at routine well baby clinics; they highlight the importance of measuring head circumference at all examinations. It has been suggested that such infants should have screening ultrasonography, ${ }^{8}$ but this may not be sufficiently precise to eliminate the possibility of a tumour.

Raised intracranial pressure leads to reduction in cerebral blood flow which can be responsible for lethargy, and ultimately for decrease in the level of consciousness. Five of our patients presented with decreased consciousness, which, in combination with extensor posturing and pyrexia, led to an initial diagnosis of meningitis. While lumbar puncture is the cardinal investigation for meningitis, it is very hazardous in the presence of raised intracranial pressure. Cerebrospinal fluid examination may also be misleading, since CSF pleocytosis and raised CSF protein are common findings in tumours. ${ }^{5}$ Thus an initial CSF examination can lead to erroneous treatment and further delay.

Nine children had symptoms and signs of herniation of the hind brain, which was secondary to raised pressure. Chronic herniation of the cerebellar tonsils through the foramen magnum can produce head tilt. ${ }^{5}$ Two of our cases presenting with head tilt had medulloblastomata, and the third had a cerebellar astrocytoma. The significance of opisthotonic posturing, seen in three children, was not recognised; these attacks were erroneously interpreted as epileptic seizures, which is a common mistake. ${ }^{3}$

Localising signs are infrequent in young children. ${ }^{7}$ Unsteadiness is the commonest local manifestation of a tumour in the posterior fossa, but is also found with frontal lesions. ${ }^{5}$ In our series, poor balance was one of the presenting features in eight of 12 children with infratentorial tumours and in one with a frontal lesion. Although unsteadiness was recognised by the parents and reported at presentation in all but one case, medical officers tended to attribute lack of balance to trivial incidents, or to immaturity. Only with the onset of further symptoms was suspicion of significant underlying pathology raised.

Failure to thrive may be a consequence of a tumour located in the hypothalamic region (the diencephalic syndrome). ${ }^{3}$ Two of the children with failure to thrive had tumours in this region; one of them spent two months in hospital being extensively investigated for other causes before a neurological explanation was considered.

Despite the high frequency of supratentorial tumours in the first 6 months, seizures are an uncommon type of presentation. ${ }^{1}$ When they occur, they tend to be focal and reflect tumour location. Thus focal seizures, particularly in association with abnormal enlargement of the head or combined with other acquired neurological deficits, should be investigated by either CT scan or MRI.

Tumours in infancy are often large at diagnosis. This may be because in many cases they are highly malignant, but a low index of suspicion and often rather non-specific symptomatology, followed by long delays in diagnosis, could be another factor.

In only one of our 21 patients was brain imaging done before the diagnostic scans. Ultrasound scanning, possible only while the fontanelle remains open, can demonstrate enlargement or deformity of the lateral ventricles and the presence of cystic tumours, but may not identify intrinsic tumours, especially if these are in the posterior fossa. Adequate definition for surgery is not obtained by ultrasound through the fontanelle. CT is virtually always adequate for diagnosis of an intracranial tumour, but much better definition is obtained with MRI, which allows multiple views and sophisticated definition, which are important in planning management, particularly when treatment by surgery is envisaged.

In conclusion, intracranial tumours present diagnostic challenges in the very young. Symptoms and signs are often non-specific, mimicking more common disorders, particularly meningitis. Neuroimaging, using CT or preferably MRI is advised when a child presents with recent onset of neurological symptoms, including vomiting, and has a disproportionately large head.

1 Duffner PK, Cohen ME. Treatment of brain tumours in babies and very young children. Paediatr Neurosci 1985-1986; 12: 304-10.

2 Mapstone TP, Warf BC. Intracranial tumour in infants: characteristics, management and outcome of a comtemporary series. Neurosurgery 1991; 28: 343-8.

3 Jooma R, Hayward R, Grant DN. Intracranial neoplasms during the first year of life: analysis of one hundred conduring the first year of life: analysis of one hund
secutive cases. Neurosurgery 1984; 14: $31-41$.

4 Allen ED, Byrd SE,. Darling CF, Tomita T, Wilczynski MA. The clinical and radiological evaluation of primary brain tumours in children. F Natl Med Assoc 1993; 85: 445-51.

5 Aicardi J. Diseases of the nervous system in childhood. Oxford Blackwell Scientific Publications, 1992: 782, 786, 816

6 Galassi E, Godano U, Cavallo M, Donati R, Nasi MT. Intracranial tumours during the first year of life. Child Nerv Syst 1989; 5: 288-98.

7 Tomita T, McLone DG. Brain tumours during the first twenty four months of life. Neurosurgery 1985; 17: 913-9.

8 Ambrosino MM, Hernanz-Schulman M, Genieser ND, Wisoff J, Epstein F. Brain tumours in infants less than a year of age. Pediatr Radiol 1988; 19: 6-8. 